CLEMENT A. TISDELL, SERGE SVIZZERO

\title{
THE ECONOMIC RISE AND FALL OF THE SILESIAN ÚNĔTICE CULTURAL POPULATION: A CASE OF ECOLOGICALLY UNSUSTAINABLE DEVELOPMENT?
}

\begin{abstract}
After a long period of substantial economic growth and population increase in the Early Bronze Age, the reason(s) for the relatively rapid disappearance of Unétice cultural populations in Silesia and the subsequent lack of population in much of their former territory for around 200 years remains unclear. Various theories have been proposed for these developments, such as changed long distance trade routes or the depletion of materials for bronze-making. However, these fail to explain why large areas formerly occupied by the Unertice cultural population remained unoccupied (or virtually so) for so long after their abandonment. We argue, on the basis of demographic and other scientific evidence, that the collapse of this population was primarily the result of unsustainable ecological development. Human-induced changes to ecosystems eventually reduced agropastoral productivity, substantially reduced the standard of living of the populations involved and resulted in the abandonment of their settlements. The extent and nature of ecological damage was such that it took a considerable amount of time for natural ecosystems to recover sufficiently before the affected areas were economically suitable for resettlement. The possibility that resource shortages for bronze-making and changed trade routes contributed to the unsustainable economic development of Silesian Unertice cultural groups is also considered.
\end{abstract}

KEY WORDS: Agropastoral sustainability - Early Bronze Age - Ecosystem change - Natural resource depletion Sustainable development - Únĕtice culture.

\section{INTRODUCTION}

Recent archaeological research by Pokutta (2013) provides demographic and other evidence indicating that the Únětice cultural (UC) population of Silesia experienced a high level of economic prosperity for 200 years or more but after that, at some time in the $18^{\text {th }}$ century BC, an economic slump occurred. She 
comments: "The end of prosperity and quite possibly the whole Silesian population of the Unertice came suddenly before 1700 BC ... The population quite literally vanished about that date and there are almost no Únětice inhumations for over 100 years until 1640 BC ..." (Pokutta 2013: 185). Taking into account the German and the broader context, Jockenhövel (2013: 728 ) states: "There are hardly any recorded graves from the end of the Únětice culture .... The end of this oncepowerful culture is still unclear. It disappeared at the start of the Middle Bronze Age." Pokutta (2013: 255-257) is at a loss to explain why the UC Silesian population suddenly declined in the $18^{\text {th }}$ century BC, and finds that the: "Silesian population soon before $1700 \mathrm{BC}$, but more likely around $1740 \mathrm{BC}$, encountered an unknown factor, which suddenly arrested the development of the group for a century" (Pokutta 2013: 255).

Archaeological research on the rise and decline of UC populations raises several interesting questions. The first set of questions involves the identification of relevant indicators of changes in the economic fortunes of UC populations. The second set of questions concerns the determination of factors leading to these changes. In this article, we explore the following as indicators of variation in the economic prosperity of the Silesian UC population: the demographic change in this population, alterations in its social structure, evidence of its changed ability to acquire or produce non-essential commodities (for example, amber and bronzes) and changed trade routes. To do this, we rely to a considerable extent on the economic interpretation of data in Pokutta (2013), but not entirely.

As for factors leading to the rise and fall of the UC population in Silesia, we hypothesise that this was mainly due to changes in the available agricultural surplus brought about by human actions rather than external forces, including external environmental forces. We follow Müller (2012) in not attributing the eventual decline in the agricultural surplus of these populations to external environmental forces and also accept the theses of Bartleheim (2009a: 34, 2013) that the economies of communities in the Early Bronze Age (EBA) in Europe, as in the Neolithic, depended primarily on agriculture.

It is argued that the main reason for the decline in the numbers of the Silesian UC population in their post-classical phase was a fall in their available agricultural surplus due to increasing population pressures as well as the growing difficulty of sustaining agropastoral yields. Nevertheless, other factors may have also contributed to the disappearance of this culture and the abandonment of many settlements associated with this culture. Some of these are discussed here. Similarly Bogucki (1996) has explained the depopulation of settlements (in Northern Poland) by Neolithic non-bronze communities as being a result of their intensive local land-use and their dense network of social obligations, both within the settlements and with nearby communities. Analogous Bronze Age cases are also available and will be discussed later.

This article is developed in the following way: first some brief background on the UC population is provided. Drawing on the empirical results of Pokutta (2013), this is followed by a discussion of changes in demographic patterns as indicators of alterations in the economic prosperity of the Silesian UC population. Subsequently, evidence on the emergence of elites and changes in their wealth are assessed as additional possible markers of the changing economic fortunes of the Silesian UC population. Because we consider the prime reason for the eventual decline in economic welfare of the Silesian UC populations to be a reduction in their agricultural surplus, processes which could have had this result are explored. Disruption and cessation of trade routes (especially involving amber) are subsequently considered as a further indicator of the changing economic fortunes of the UC population. Although bronze production and long-distance trade involving the exchange of bronze for amber are frequently seen as central features associated with the economic development of UC populations, we argue that Silesian UC settlements are unlikely to have disappeared as the result of an eventual shortage of materials for bronze-making, or because of changed trade routes which disrupted their long-distance trade.

\section{SOME BACKGROUND ON THE ÚNĔTICE CULTURE}

The Únĕtice culture emerged in Central Europe in the EBA. It was present, for example, in Czechia, Slovakia, a part of eastern Austria, much of contemporary Germany and southwest Poland. It derives its name from archaeological finds in a cemetery located in the village of Unětice outside Prague. Their agricultural methods enabled the UC populations to increase their economic fortunes and yielded an agricultural surplus (Pokutta 2013). This agricultural surplus enabled bronze-making to develop and to reach new heights and in due course, also facilitated long- 
distance trade in bronzes, mainly in return for luxury products, such as amber. Its development also resulted in the emergence of a dominant or elite class (in the northern part of its distribution); traditionally described as a chiefly class, members of which probably assumed a variety of functions, including acting as priests (Bogaard et al. 2013, Knipper et al. 2016, Pokutta 2013). The social and political organisation of UC populations varied temporally and geographically (Pokutta 2013).

Jockenhövel (2013: 725) points out that the Aunjetitz or Únětice culture (2300-2200 to 1600-1500 BC) extended from areas in "the middle Danube (south-west Slovakia, Northern Lower Austria) across Moravia and Bohemia to Central Germany, and as far away as Silesia and Great Poland." Jockenhövel mentions that common features of the Únětice culture included similar object forms and burial sites and the adoption of new technologies, such as the production of tin-bronzes and the use of improved metal-working techniques. In most cases, Únĕtice settlements were surrounded by lands containing inhabitants continuing the late Neolithic tradition (Jockenhövel 2013: 725), and this included UC settlements in Silesia (Pokutta 2013).

Groups embracing the Únĕtice culture existed for about 700 years (approximately from 2200-1500 BC, that is until the end of the EBA) and because they were present over a large area of Central Europe (Müller 2012: 258), they experienced considerable differences in local environmental and related conditions. A special feature of those adhering to the Únětice culture is that they were the first producers of bronzes in Central Europe (Roberts et al. 2009) and at their zenith manufactured high quality bronzes (Pokutta 2013). Most settlements would not have had direct access to local tin (Harding 2013a: 374-375) and copper deposits (Harding 2013a: 372-374, O'Brien 2013).

Indeed, given the vast territory associated with Unertice culture and the considerable differences in local environmental, some groups had access to metal ores (copper, tin and gold), e.g. in south-west Slovakia and eastern Moravia where a considerable development of metallurgy was found at the end of the Eneolithic (Batora, 1991, Harding, 2000: 199-201). On the contrary, for the groups located within the area of Poland (including Silesia), there is no reliable evidence of metal ores being exploited during the Bronze Age (Piwocki, Przenioslo, 2004). Bronzesmiths in settlements without these deposits were dependent on obtaining supplies of unwrought copper or tin (usually in the form of ingots) from settlements having tin or copper deposits.

Archaeologists have placed considerable weight on variations in finds of precious objects, particularly metals (for example, bronzes and amber) in graves, as markers of socio-economic changes in Únĕtice societies. Müller (2012: 259) states that quantitative and qualitative differences in deposits of artefacts deposited in individual UC graves at first increased and then decreased, at least in Central Germany. In the proto-UC phase little difference is found between the depositions of artefacts in individual graves. This is indicative of little social and economic inequality. In the classical UC phase, precious metal objects are found in most (if not all) graves but some have more such objects than others and their accompanying mounds are much larger than the rest. In the late UC phase, there are few graves or none at all.

The overall pattern which emerges is that little (if any) social and economic inequality existed in protoUC tribes. However, as the keeping of livestock and the cultivation of crops developed, significant social and economic inequality evolved in the Silesian UC group. A small group emerged as the governing class and this may have consisted of priests and tribal chiefs. Possibly, this inequality was largely reflected in differences in the extent of ownership of livestock (Pokutta 2013: 204). In the late UC phase, it seems likely that social inequality did not disappear in the Silesian UC population. However, it is suggested in this article that individual members of the dominant class had reduced economic means to furnish their graves for agropastoral reasons which are discussed later. Additionally, materials needed to produce tin bronzes probably became scarcer, and consequently, increasing scarcity occurred on two fronts.

\section{DEMOGRAPHICS AS AN INDICATOR OF THE CHANGING ECONOMIC PROSPERITY OF THE SILESIAN ÚNĔTICE CULTURAL POPULATION}

Demographic changes can be a useful indicator of variations in income per capita of human populations. Based on her isotopic analysis of $\operatorname{diet}{ }^{13} \mathrm{C}-{ }^{15} \mathrm{~N}$ and strontium isotopes of skeletal remains from sites in the Wroclaw area of Silesia (Poland), Pokutta (2013: 186) infers a general relationship for changes in the UC population in Silesia as a function of time in the EBA 
(2450-1600 BC) and provides estimates of the total number of immigrants in this population. These are identified in given chronological phases starting from the proto-Únětician phase and ending in the postclassical phase. The Wroclaw area contained the major concentration of the UC population in Poland. Her sample of skeletons is assumed to indicate basic patterns of demographic change in Silesia. This identification of the number of immigrants in her sample is particularly relevant for identifying likely alterations in the economic prosperity of the UC population in Silesia. Table 1 summarises Pokutta's pertinent demographic data.

\section{INSERT TABLE 1}

Pokutta's results indicate that the Silesian UC population was more numerous in the period 20001900 BC compared to that in the period 2100-2000 BC. It then remained stationary in the time-interval 2000-1800 BC. Subsequently, in the period 1800-1600 $\mathrm{BC}$, the magnitude of this population declined rapidly to a level lower than before 2250-2100 BC. An important question is why did the level of this population (and the percentage of immigrants in it) at first increase and then decline markedly? We hypothesise that this reflects changes in the economic

TABLE 1: Demographic features revealed by Dalia Pokutta's examination of skeletal exhumations in the Wroclaw area of Silesia. Rounded to the nearest whole number. Source: numbers have been derived from Pokutta (2013: Fig. 213) and the percentages have been calculated by authors.

\begin{tabular}{llll}
\hline Period BC & $\begin{array}{l}\text { Number of } \\
\text { individuals }\end{array}$ & $\begin{array}{l}\text { Number of } \\
\text { immigrants }\end{array}$ & $\begin{array}{l}\text { Immigrants } \\
\text { as a } \\
\text { percentage }^{(a)}\end{array}$ \\
\hline $2250-2100$ & 6 & 0 & 0 \\
$2100-2000$ & 3 & 1 & 33 \\
$2000-1900$ & 16 & 8 & 50 \\
$1900-1800$ & 16 & 5 & 31 \\
$1800-1700$ & 7 & 1 & 14 \\
$1700-1600$ & 2 & 2 & 100 \\
\hline
\end{tabular}

prosperity of the UC population. Both changes in the total population and in the level of immigration are relevant to this conclusion.

The Silesian UC populations depended primarily on agropastoral activities for their livelihood (either directly or indirectly, as is explained later) and its members were able (at least for some time) to generate initially a considerable agricultural surplus (Pokutta 2013). In these circumstances, as suggested by Childe (1936), restraints on population growth (which were common in foraging communities) would have been significantly relaxed because offspring could become productive at a much earlier age than in foraging societies (Hassan 1981). For various reasons (discussed later), agricultural productivity would have remained high before resource scarcity or natural resource deterioration became a constraint. Therefore, a Malthusian-like increase in population levels could be expected before these communities started to experience a noticeable decline in their per capita income, that is until they moved closer to the carrying capacity of their local area (Hassan 1981: Ch. 10). From Table 1, if the proto-UC population is ignored, it can be deduced that the numbers of the local population in Pokutta's sample show the following sequence for each century beginning in $2100 \mathrm{BC}: 2,8$, 11, 6 and 0 . Hence, the rate of increase of the local population was very rapid in the period 2000-1900 BC (rose by 6 , that is by $300 \%$ compared to the previous century). The rate of increase in the local population moderated in the next century (1900-1800 BC) compared to the previous one. Then, the increase in the number of locals in the sample is three, a rise of $37.5 \%$. However, in the next century (1800-1700 BC), the local population declines by about $45 \%$, prior to being completely unrepresented in the sample in the period 1700-1600 BC. This pattern suggests a period of increasing economic abundance until about 1900 $\mathrm{BC}$, followed by reduced economic prosperity (or income per capita) in the period 1900-1800 BC. This is followed by demographic signs of increasing economic deprivation. Pokutta's data relating to immigration are consistent with this pattern of economic development.

Pokutta's skeletal analyses indicate that immigrants in the Silesian UC population rose substantially in numbers and as a proportion of this population in the period 2000-1900 BC compared to 2100-2000 BC. Immigrants might have been attracted to Silesian UC settlements because in Silesia living standards were higher in these settlements than in their own. However, 
between $1900 \mathrm{BC}$ and $1700 \mathrm{BC}$, the proportion of total immigrants in the Silesian UC population declines. This suggests that economic conditions in these settlements began to decline and therefore, they were less attractive as a magnet for immigrants. Therefore, migrating to these areas may not have been economically attractive anymore. Furthermore, as economic conditions became more difficult in Silesian UC settlements, immigrants would have been less welcome, and possibly would have been increasingly denied economic opportunities by local populations. Although economic differences between regions are not the only ones influencing migration patterns, they are recognised by economists as usually being very important (Todaro 1969). Note that in the initial period in which the proportion of immigrants in Pokutta's sample began to decline (1900-1800 BC), the total level of the population represented by this sample remained stationary. This was possibly because the resident populations experienced some inertia in responding to deteriorating economic conditions. For example, they may have begun to consider the possibility of emigration but could have been slow to adopt this option.

Once economic conditions deteriorated significantly in SW Poland, increased emigration may have occurred. This could have been initially to nearby communities with somewhat better economic conditions, but they too may have begun to experience a decline in their economic fortunes. Ravenstein's type of leap-frog migration may have occurred (Ravenstein $1885,1889)$. These migrations could have resulted in a domino-effect of decreasing economic fortunes, and this could have happened without leaving much archaeological evidence, especially if the migratory paths of the emigrants were quite diffused and the process was slow, as it might have been. Some may have even joined populations not subscribing to the Únĕtice culture.

A further intriguing matter raised by Table 1 is why (in the period 1700-1600 BC) was the very low level of the Silesian UC population apparently composed entirely of immigrants. Were they searching for a better economic life because of deteriorating economic conditions elsewhere? Since the number of immigrants in Pokutta's sample in this period is quite small, this could indicate that they were unable to significantly improve their economic lot by migrating.

Figure 1 displays the visual pattern of demographic changes in Silesian UC settlements in the period 22501600 BC, assuming that the data in Table $l$ is reasonably representative of those changes. It indicates a relatively

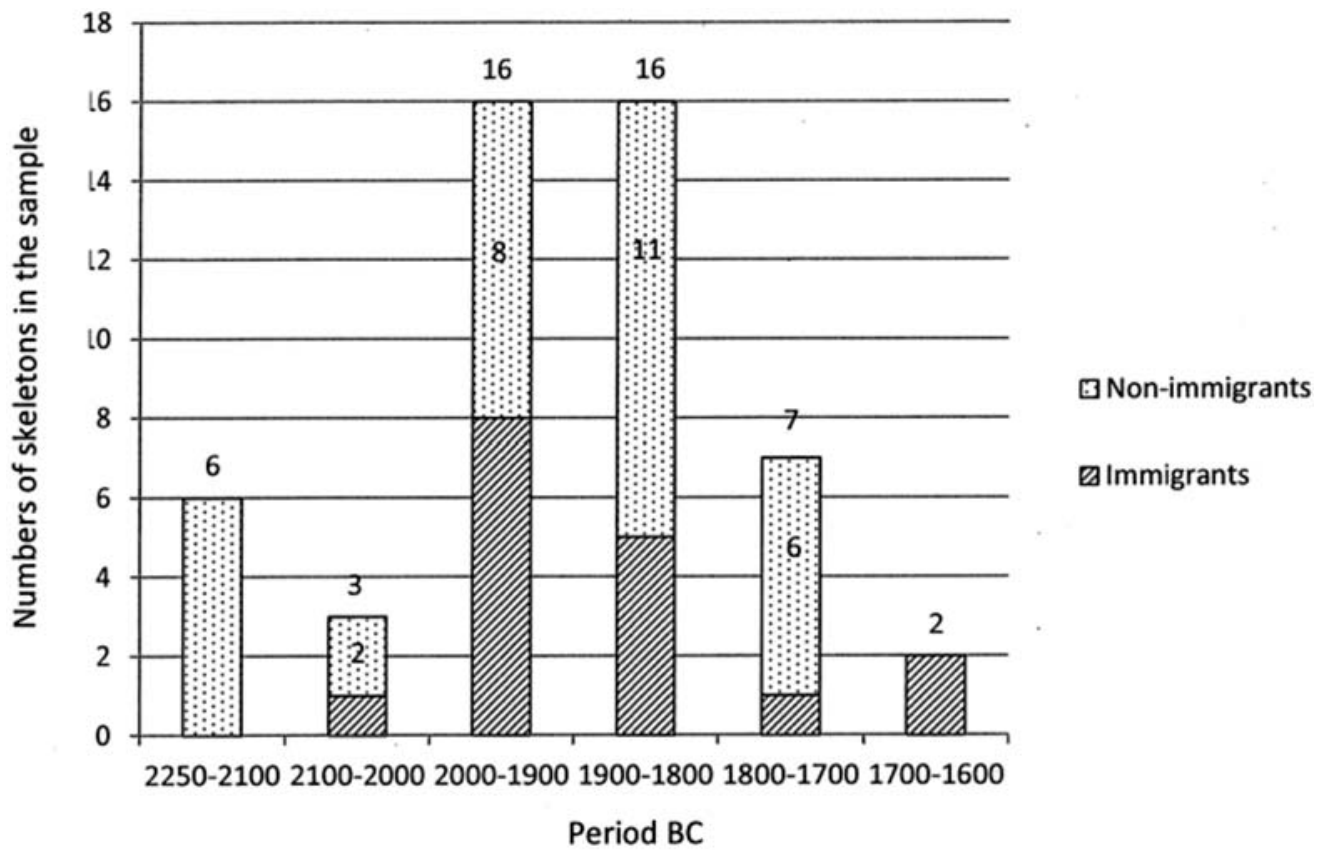

FIGURE 1: A bar chart indicating trends in levels of the Únĕtice cultural population in Silesia and their composition in terms of migrants and non-migrants in the period 2250-1600 BC, based on Table 1. 
rapid rise in the level of the Silesian UC population, with this level reaching its peak between 2000-1800 $\mathrm{BC}$, followed by a comparatively rapid decline. Of somewhat greater interest is the proportion of immigrants in the total population. Initially, no immigrants are in these samples. After that, their numbers and their proportionate representation in the sample increase and then from 1900 onwards, declines until the period 1700-1600 BC is reached. In this last period, the whole sample consists of immigrants. This suggests that most of those indigenous to these settlements had migrated by then or disappeared in some other way. While Pokutta's sample is small (and would not satisfy the usual rules for random selection), it is our best available evidence about demographic changes in the UC population of Silesia. Nevertheless, hypotheses based on these data should be treated at this stage as conjectures. In particular, as pointed out by Montgomery and Jay (2013), there are significant limitations to the use of skeletal isotope analysis to infer population mobility and the nature of the diet of Bronze Age populations.

How might one explain the changes in economic conditions experienced by the Silesian UC population? Could it have been due to human-induced environmental change and natural resource depletion resulting from human exploitation of their resources? As specified later, we argue that this may well have been so. If so, it provides another example of an ancient community that experienced unsustainable economic development caused by human alterations to the environment and natural resource depletion (see examples in Cunliffe 2015, Diamond 2005). Similarly, it is widely believed that human-induced environmental change led to the collapse of the Mayan civilization in Central America. According to Haywood (2010: 94): "Studies of sediments recovered from lake beds reveal that [in their late Classic phase] the Maya had become the victims of their own success. The late Classic was a time of massive deforestation, erosion and soil exhaustion. Over-exploitation of rainforest soils brought about the collapse of agriculture." However, climate change and increased aridity also appear to have played a key role in this collapse (Haug et al. 2003). Anthropogenically-induced environmental deterioration in EBA has also been detailed in some UC settlements in the Czech Republic (Ernée et al. 2009, Ernée et al. 2011).

Pokutta's findings about the pattern of immigration in the UC Silesian population do not seem to apply to all UC populations. Knipper et al. (2016) concluded, after examining skeletal remains from UC burials in Central Germany, that immigration was not significant there. The reason for the apparent lack of immigration in these settlements is unknown. One possibility is that there were greater social restrictions on immigration there than existed in Silesia. As a result, the population of UC settlements in Central Germany may have increased in the classical phase at a slower rate than those in Silesia because the former depended only on natural population increase. Consequently, any economic and ecological problems arising from increasing populations may have been delayed in Central Germany compared to their emergence in Silesia, might have been negligible.

Before considering whether the pattern of demographic change of the UC Silesian population was due to human-induced environmental change which altered the availability of agropastoral commodities, it should be observed that Pokutta's demographic data do not indicate that the economic demise of the Silesian UC population was sudden and caused by a cataclysmic unknown event occurring around 1740 BC, as she claims (Pokutta 2013: 185). There are already demographic signs of increasing economic stress in the $19^{\text {th }}$ century BC during which the rate of local population growth declined and so did immigration, as was shown above. The situation worsened in the $18^{\text {th }}$ century BC because both the level of the local population decreased and the inflow of migrants fell even further compared to that in the previous century. This supports the view that the stressors affecting the UC population of Silesia were cumulative in magnitude, began to be important already in the $19^{\text {th }}$ century BC and subsequently became a serious problem in the $18^{\text {th }}$ century BC. This pattern is consistent with the occurrence of growing population pressures and deteriorating environmental conditions, most likely caused primarily by human economic activity, particularly agropastoral activity and deforestation in the vicinity of settlements. Let us consider this scenario.

\section{CHANGES IN THE AGROPASTORAL SURPLUS AS THE MAIN CONTRIBUTOR TO THE ECONOMIC RISE AND COLLAPSE OF ÚNĔTICE CULTURAL POPULATION IN SILESIA}

Pokutta (2013: 247) identifies agriculture as "the key to prosperity of the whole Únětice society [in 
Poland] for hundreds of years" and claims (Pokutta 2013:246) that "the Únětice culture can be seen as the first archaeological unit introducing [intensive] manuring into the territories of Poland." She also points out that manuring rapidly became a normal practice of the UC Silesian population, and played a significant role in their intensification of agriculture. In the early phases of UC settlement, it helped provide increased supplies of food for a rising level of population. She wonders why there was an increase in agricultural intensification in the Wroclaw area, because the Wroclaw Plain contains quite fertile soils, and interestingly, she links increased manuring to growing population pressure. She states: "Evidence shows that in the early Únětice phase, we are dealing perhaps with hundreds of individuals, but in the classic phase, this population represents thousands of people living in a relatively confined territory. In such cases, fertilization might have been the only option to meet growing food needs" (Pokutta 2013: 247).

In Poland during the EBA, the keeping of livestock was very important. Domestic livestock included mainly cattle. Pigs, sheep and goats were of secondary importance and some horses were present (Czebreszuk 2013: 774). Pokutta (2013) provides evidence of the major role of livestock in the UC economy of Silesia. There was also significant crop production, including the growing of grains (wheat was important), and some legumes, but the range of plants cultivated altered with the passage of time (Czebreszuk 2013: 774).

In considering the pattern of agropastoral development in Silesia and its implications for variations in the standard of living of its UC population, attention needs to be given to the following:

- Environmental deterioration, largely but, not entirely, due to agropastoral activities.

- The operation of the economic law of eventually diminishing returns to increased use of variable resources in agriculture (such as manure), other things being held constant.

- The extent to which technological progress was able to offset negative effects on the level of agropastoral productivity due to the forces mentioned above.

The first effect can be envisaged as shifting the agropastoral production function downwards; the second one corresponds to a movement along this function resulting eventually in diminishing returns; and the third effect results in a movement of this function upward, if the technological change is productivity-enhancing. The consequences for the level of agropastoral output of a population (and therefore, their agropastoral surplus) depends on the combined impacts of these three forces. It is hypothesised that in the early years of the establishment of the UC population in Silesia, these relationships were favourable to an increase in living standards but subsequently, their combined effect became unfavourable, most likely beginning in the $19^{\text {th }}$ century BC, given Pokutta's demographic results. Let us in turn consider the influences on agropastoral production of changes in environmental quality, alterations in the marginal productivity in response to efforts to increase agricultural production to satisfy the needs of a growing population, and technological progress.

In the initial years of establishment of the UC population in Poland, their impact on the natural environment would have been slight, but there is evidence that as this population increased in magnitude, significant adverse environmental impacts were generated by their anthropogenic activities. The often quoted analogous case from the EBA is that of Bruszczewo in Greater Poland which is a province adjoining Silesia. Czebreszuk (2013: 774-775) summarizes this case as follows:

"The steady and intensive occupation of the land had a significant impact on the environment. Wooded areas in the immediate vicinity of the settlement (2$3 \mathrm{~km}$ ), composed mainly of small, scattered groups of trees (Müller et al. 2010: 232-237), were drastically depleted (Müller et al. 2010: 78). Human activity (farming) and cattle grazing led to the degradation of the top humus layer and intensified erosion. The consequences of the changes in the water composition in the adjacent lake were even more serious. Studies have shown the presence of algae, eggs of human and animal parasites and spores of coprophilous fungi. It is very likely that during some periods in the Bronze Age the water in the lake was undrinkable or even toxic to humans and animals. In the case of Bruszczewo, we can assume that the destruction of the environment by humans was the chief reason for the abandonment of the settlement."

Although it applies to a later period, namely the Middle Bronze Age and the Late Bronze Age and is located in a different area in Poland to Silesia (the Carpathian Foothills), archaeobotanical research by Moskal-del Hoyo et al. (2015) is also of indirect relevance to the type of changes which most likely occurred as a result of agropastoral development and firewood collection by Silesian UC populations. They found that areas close to their focal settlements were 
deforested and used for farming and for grazing by domestic animals. However, 'oak-beam' forests developed in slightly more distant areas from the central part of the settlement. (Moskal-del Hoyo et al. 2015: 439). The hornbeam $C$. betulus (present in these forests) "is a very competitive species [of tree] which is capable of very rapid colonization, especially of disturbed forest formations. Different human actions favoured the spread of $C$. betulus since it is lightdemanding, resistant to mechanical damage related to animal browsing or grazing and regenerates vegetatively." Its spread is favoured by repeated clearings and coppicing. Consequently, its spread reduces the grazing area available to livestock. Furthermore, Moskal-del Hoyo et al. (2015) also reported feather grass established itself (mainly as a result of habitat change caused by pastoralism) and that livestock avoid this plant because its awns can lodge in their intestines.

In addition, Moskal-del Hoyo et al. (2015) make some interesting observations about weeds in cultivated areas. They document the presence of several species of annual weeds in previously cultivated areas. They find that cultivated plots were not used for a long period because the weeds found in them are annuals, not biennials and perennials (Moskal-del Hoyo et al. 2015: 437). The reasons why there was relatively rapid abandonment of fields used for cropping could have been twofold: it may have been a response to the growing presence of annual weeds in cultivated areas, and the declining fertility of their soils as a result of their repeated continuous use.

Whether or not similar changes in plant communities (having associated negative effects on the sustainability of agropastoral production) occurred in Silesian UC areas requires archaeological investigation. However, as indicated above, human-induced changes in the natural environment would have made it increasingly difficult to sustain the level of agropastoral production in these areas. In the absence of mitigating factors, such as sufficient rapidity of offsetting technological progress, cumulative soil loss and deterioration in soil quality (and other types of human-induced environmental change) would have increased the difficulty of sustaining the level of agropastoral production. This is likely to have happened in the Wroclaw area given Pokutta's assessment that population densities there eventually reached substantial levels (Pokutta 2013: 247) before the decline of Wroclaw's UC population occurred.

In light of the above, the eventual adverse ecosystem changes in UC settlements in Silesia could have included the following:
- Increased soil erosion due to reduced natural vegetation cover.

- Reduced soil fertility, and depth due to erosion.

- Greater invasion by weeds of land used for cultivation and grazing. This includes invasion by woody weeds and tree species unpalatable to livestock, as well as annual weeds in cultivated areas.

- Possibly, increased attacks by wolves and other vertebrate predators on livestock. However, wild carnivores would not have been the only livestock pests that the UC population would have had to contend with. Crops would have been damaged or lost to deer (herbivores), wild boar (omnivores) and other pests, such as insects and diseases of plants may have become more prevalent.

Weed invasions can have serious negative consequences for agropastoral productivity and may have been a major contributor to the declining prosperity of the UC population in their post-classical phase. More archaeological evidence about weed invasions would be useful, and is achievable given that evidence about the presence of weeds is available for some other prehistoric situations in Europe (Bogaard et al. 2013, Moskal-del Hoyo et al. 2015). It might be noted that livestock are selective grazers or browsers. Over long periods of time, livestock are liable to change natural vegetation cover by increasing the dominance of plants which are unpalatable to them (Moskal-del Hoyo et al. 2015). The consequence is reduced livestock productivity and livestock carrying capacity. Furthermore, unless appropriate collective measures are in place, the use of commons for shared grazing by livestock results in livestock densities increasing to levels which reduce total livestock production. It is impossible to tell what social restrictions (if any) were applied to the grazing of livestock on common land by UC residents. Nevertheless, elevated livestock densities would have hastened soil erosion.

Based on pollen samples in lakes, Kneisel (2012) reviews the evidence for deforestation mostly in Poland and for northern Germany. This evidence supports the view that substantial deforestation occurred during the economic expansion phase of the UC population and that reforestation occurred during the decline of this population. As for soil erosion, there is evidence of this in Poland (Müller et al. 2010), and for this from nearby portions of north central Germany (Dreibrodt et al. 2010). However, Kneisel (2012: 227) while conceding that changes in the environment contributed to the abandonment of the UC settlements in the area between the Harz Mountains in Germany and the 
Warta River in Poland during the late Únětice cultural EBA, doubts whether this was the main reason for their abandonment. She is of the opinion that a variety of factors contributed to this outcome. By 1700-1600 BC, these former settlements were virtually bereft of human population, and were not again significantly repopulated for a long while. Kneisel (2012: 227) suggests changed trade routes and social upheavals were also important in the decline in the northern distribution of the UC population. However, to some extent, social upheavals and reduced trade may have been a result of declining economic fortunes in northern UC areas, declining economic conditions being a result of unfavourable ecosystem change.

Because there is a gap of up to two centuries before significant evidence of resettlement of these areas occurs (Pokutta 2013), this seems to support the hypothesis that adverse human-induced changes to natural ecosystems were the main contributors to the decline in the standard of living of their UC population. The evidence of a long period of depopulation is primarily based on the lack of graves, but as one reviewer (of the draft of this article) pointed out, this could be due to a change in burial rites, for example, cremations rather than burials. Nevertheless, the recovery of these ecosystems could have taken a considerable amount of time given the changes posited. After two centuries, dominant tree species and other vegetative species (climax species which were not always conifers) might have re-established themselves and recuperation in soil fertility would have been possible. Also the subsequent settlers may have migrated to these areas with superior agricultural technologies compared to those available to their previous UC inhabitants.

Yet, Kneisel (2012: 227) maintains that it is difficult to imagine on the basis of the population count assumed for the EBA that demographic factors could have led to large-scale destruction of the natural environment. Nevertheless, only selected areas of land probably would have been used for agropastoral activities given the available technology and the nature of local environments. Hence, these areas may have been used with increased intensity as their UC populations rose. The hypothesis that adverse ecosystem change induced by human activity and declining marginal productivity of agropastoral activities were major factors in the eventual decline of Silesian UC populations cannot be dismissed easily, especially in the light of evidence at odds with that of Kneisel, for example, the research results of Pokutta
(2013). She finds that during their classical phase, the Silesian UC population of the Wroclaw area reached relatively high densities in relation to the available amount of arable land. She points out that in the period 2000-1800 BC approximately, Silesian settlements and cemeteries were very close to one another (not more than 1-2 km apart) and had a combined population of twenty to forty thousand. Members of each settlement were squeezed into a limited area of fertile land. Therefore, the adverse impacts of the population increase on the natural environment (especially as population levels approached their zenith) are unlikely to have been minimal.

The second consideration has to do with a reduction in the marginal productivity of agropastoral activity in response to its intensification and extension in order to meet the needs of a growing level of population. In the early phases of the economic development of UC settlements in Silesia, the marginal productivity of their agropastoral activities probably did not decline. This was because population levels were insufficient to require the utilisation of all high quality arable land. However, at some point in time, as a result of increasing population, the law of eventually diminishing returns would have come into operation. Consequently, a relationship similar to that assumed by Weisdorf (2005) may have applied (see also Tisdell, Svizzero 2015b, 2017a), that is, economic returns from increased agropastoral activity (in response to increased population levels) at first remained constant but subsequently, declined once the level of population exceeded some threshold value. The stage of diminishing marginal productivity from agropastoral activity may arise from either the intensification or the extension of agriculture, or both. Childe (1957: 4) states that: "the new industry (i.e. Bronze production) revealed, but only in embryo, the solution to the contradiction of the Neolithic economy: the sole means of providing for an expanding population was to bring fresh land under cultivation or grazing (...). When all land suitable for exploitation ... was fully occupied ... that would mean a reduction in the standard of living." However, this is not the only possible way to cater for a growing population: intensifying the management of land already used for agropastoral activity is another. Both can be important and probably were in UC settlements. Note that marginal lands are usually more susceptible to rapid reduction in productivity when used for agropastoral purposes than are lands of better quality. For example, 
they are subject to a faster rate of soil erosion and to a speedier decline in their fertility.

Observe that Childe's statement (quoted above) requires qualification because it does not take account of the different qualities of land available for agropastoral production, and it takes no account of diminishing returns from the increased intensification of agropastoral activities. For example, according to standard economic principles, increased application of manure to a given plot of land, as well as labour, results in a decline in the marginal amount of crop output, everything else held constant. Pokutta (2013) stresses the significance of crop manuring in increasing the yield and the nutritional value of crops grown by the Silesian UC groups. It should however, be noted that crop manuring and intensive land management were practiced in Europe well before the appearance of the Unĕtice culture and therefore were not innovations of theirs (Bogaard 2004, Bogaard et al. 2013). As a response to growing population pressures, the Silesian UC population most likely increased their intensity of the management of crops, for example, by increasing manuring and weeding activity. These activities are labour intensive and subject to diminishing marginal productivity. Furthermore, the supply of livestock manure is not unlimited. An upper limit to its availability is set by the level of the population of the livestock. Also, the amount of labour needed to collect it depends on its location, the extent to which it is scattered, and its proximity to the cropland to be fertilized.

The livestock carrying capacity of the land occupied by UC communities was limited. This would have set an upper limit to its livestock carrying capacity and therefore, the availability of animal manure. Moreover, as the UC population in the area increased, there may have eventually experienced some increased competition between this population and their livestock for food. For example, the amount of land available for livestock grazing probably declined as an increased quantity of land was needed for growing crops for human consumption. Furthermore, less land may have remained for producing crops to help feed livestock in the winter, for instance. These effects combined with the declining quality of grazing land (due to environmental changes already discussed) would have made it difficult eventually for the Silesian UC population to increase (or even maintain) their livestock numbers.

Residents of UC settlements in Silesia relied on a combination of agropastoral products and foraging in the wild, as well as hunting and fishing, to provide them with necessities. Their proportionate contributions varied (Pokutta 2013). As population densities increased, foraging and hunting opportunities may have declined. This might have been important in poor seasons and in the winter. This trend would have added to the eventual declining economic fortunes of the Silesian UC population.

A third consideration is the contribution of improvements in agropastoral methods of production in offsetting reduced agropastoral output due to environmental deterioration, as well as its role in combatting diminishing returns from extra production effort. Even though methods of agropastoral production adopted by the UC population in Poland altered - there were, for instance, some changes in the types of crops grown and some alteration in the composition of their holdings of livestock (Czebreszuk 2013: 774) - these changes were (apparently) inadequate to offset the negative effects on the per capita level of agropastoral production of the trends just mentioned. Further research is needed to pinpoint the extent to which the adoption of new agropastoral methods (if any) helped to reduce the eventual decline in the per capita level of agropastoral production of the Silesian UC population. The role of technological progress in offsetting the type of effects mentioned above has been discussed in economics since the early $19^{\text {th }}$ century (Tisdell 2005 : 12-18) concentrating initially on the second of the above relationships. In recent decades, the first one (counteracting adverse environmental change) has been receiving the lion's share of attention (Tisdell 2015).

\section{IS THE PATTERN OF CHANGES IN FINDS CONSISTENT WITH RISING FOLLOWED BY FALLING PROSPERITY OF THE UC SILESIAN POPULATION?}

Successful agricultural development can be a powerful force resulting in the emergence of an elite or dominant class (Childe 1936, Svizzero, Tisdell 2014, Tisdell, Svizzero 2015b, 2017b). The Silesian UC population adopted agricultural methods which during their era of economic growth, enabled them to generate an agricultural surplus. In turn, this could be used to support non-agricultural activities, such as various activities associated with bronze-making. This agricultural surplus eventually resulted in increased economic inequality and the emergence of an elite class (Pokutta 2013), and enabled non-essential goods 
(luxuries), such as tin bronzes and amber, to be obtained, particularly by the elite.

However, the moderately wealthy status attained by the elite in the classical phase of the existence of the UC population did not last. In the post-classical phase, judging by finds in graves, the wealth of individual members of the elite declined and social inequality decreased. Müller (2012: 259-260) reports: "In Classical Únĕtice, there are graves e.g. with rather differing number of metal grave goods, clearly the few burials in large grave mounds contrast quantitatively and qualitatively in their furnishing as well as concerning the extent of their mounds in comparison to the rest of the burials (Zich 2010). Examples of over furnishing with weapons and with ...precious metal artefacts placed only in the richest graves indicate social inequality (Hansen 2010). In late Únĕtice the furnishing of individual graves with burial objects and therefore the verifiability of difference [in social inequality] decreases."

Furthermore, Dalia Pokutta reported in 2016 (pers.com.) that in the later stages of the presence of the UC population in Wroclaw, recycled bronzes as well as doped (adulterated) ones became more frequent in finds. This suggests that increased sacrifice was needed to add to the existing stock of tin bronzes. This rising sacrifice was most likely attributable to the eventually declining agropastoral surplus of the UC population or to the growing effort needed to produce quality bronzes, for example, due to the declining availability of quality ores, particularly tin. Probably both factors were important.

The above observations consistent with the proposition that the economic prosperity of the Silesian UC population after rising substantially at first, subsequently declined due to economic hardship. Eventually, long-run deterioration in ecosystems and increasing populations would have adversely affected the incomes of all residents of Silesian UC settlements, including those of the elite. A factor contributing to the decline in the presence of prestige goods in graves in the late Unertice in Silesia might have been that the elite had a reduced economic surplus available to them due to falling agropastoral productivity and their numbers may have risen so that their shares in the surplus would have become smaller. Furthermore, it may have become more difficult or costly for the elite (in terms of the amount of food needed to be sacrificed) to obtain precious non-essential objects, such as tin bronzes and amber. All three of these factors could have been important.
However, as one reviewer of the earlier version of this article pointed out, one should be wary about evidence of changes in the furnishing of graves and alterations in finds in hoards in inferring changes in economic prosperity. Nevertheless, evidence from these sources (as revealed by the research of Pokutta, 2013 ) is consistent with a rise and a subsequent fall in the economic fortunes of the Silesian UC group.

It is not clear how the Silesian UC elite obtained greater wealth than that of others. Possibilities include: - The ownership by the elite of more productive assets as well as a greater quantity of these assets than those available to commoners, e.g. agricultural land used for crops and more livestock (as suggested by Pokutta 2013);

- The voluntary or involuntary supply of labour to the elite; and

- The voluntary or involuntary supply of agricultural produce to the elite.

However, Pokutta (pers. com.) believes that the last two possibilities do not apply to the Silesian UC population (see also Pokutta 2013). Whatever was the case, if the level of the Silesian UC population eventually increased at a rate that could not be supported by the rise in agricultural productivity or the availability of food supplies, this would have resulted in the declining economic prosperity of this population. Lack of constraints on either the population growth of commoners or of the elite (or both) can give rise to this type of Malthusian result (see Tisdell, Svizzero 2015b, 2017b).

\section{THE RELATIONSHIP BETWEEN THE PRODUCTION OF TIN BRONZES AND THE ECONOMIC DEVELOPMENT OF UC SOCIETIES}

The above analysis suggests that declining agricultural productivity (the increased difficulty of maintaining per capita agricultural output) was possibly the main reason for the decline of the economic prosperity of UC settlements in Silesia in their post-classical phase, that is, after $1800 \mathrm{BC}$. However, there are alternative (or complementary) explanations of the eventual decline in the prosperity of UC groups which need to be considered, namely that this was due to the increasing scarcity of materials for producing bronzes or to changed long-distance trade routes, or a combination of both. Let us consider these views in turn. 
We are of the view that increased stocks and growing production of (tin) bronzes were a result of greater wealth (generated by an agricultural surplus) rather than the source of it. This view accords with that of Bartelheim (2009a, 2013). A detailed account of Bartelheim's hypothesis is given in Bartelheim (2009a). He summarises his conclusion as follows: "There are many archaeological indicators, particularly the location of population centres and their long existence, which show that the Early Bronze Age economy of central Europe was primarily directed towards subsistence production following a tradition which went back to the Early Neolithic. As these centres can also be regarded as economic foci, it seems likely that agricultural production created the most wealth. The surpluses could be used to purchase products not essential to survival - and these include the majority of metal products which have been found. Trade in high-quality metal products for the agricultural-based centres may have been profitable as well" (Bartelheim 2009a: 43).

His empirical evidence for this conclusion relies mainly on the fact that finds of bronze objects are concentrated in localities which have favourable conditions for agriculture, such as very fertile soils. $\mathrm{He}$ includes Lower Silesia in this category.

Whether or not a large economic surplus was required for the commencement and development of a bronze industry has been subject to debate. Kienlin and Stöllner (2009) argue that a social hierarchy and a large economic surplus were not prerequisites for the commencement and continuation of Bronze Age mining in the EBA AI. They base their findings on observations from copper mining in the north European Alpine region. Their view is also consistent with the opinion of Cunliffe (2015) about the commencement of copper-based mining and metallurgy in the Middle East. Nevertheless, those involved in these activities must have had available spare time (a surplus of time) to do this. If they allocated so much time to these activities that they were unable to supply all their essentials for life, they would have had to rely on others to cover this deficiency. This deficiency could have been met by the supply of provisions from local sources or by imports of some essentials, or by a combination of both.

The involvement of UC groups in interregional trade was most likely confined mainly to easily transportable highly valued products. For example, tin bronze products may have been mostly (but not always) exchanged for amber. Salt was also an important trade item (Bartelheim 2009a) but several other items were also exchanged. All settlements mining tin and copper ore for bronze production, smelting these or casting these, would have required an economic surplus to do so. In the absence of significant imports of necessities, the economic surplus would have had to be generated locally. On the other hand, if much food was imported in return for the export of bronzes (which is unlikely), dwindling bronze production would have negatively impacted on the economic prosperity of the UC communities committed to bronze production (Tisdell, Svizzero 2015a). Conversely, if the supply of necessities able to be imported by these communities became scarce, this would have also adversely affected their prosperity.

Possibly, the main reason why UC settlements did not import large amounts of necessities is that, particularly in inland areas, the transport costs of doing so would have been high. However, it is known that some interregional trade in food and food-related items did occur, for example, of livestock (cattle on the hoof) (Lasak, Furmanek 2008). Transport costs by sea or river would have been lower for some items such as grains than by land. Therefore, for instance, in the Mediterranean, there would have been greater scope to trade in necessities of this type than in inland areas. Inland trade was probably conducted (in some instances) in relatively short geographical stages with traded goods being exchanged at the borders of fairly small-sized territories. This accords with a suggestion of Childe (1957). This might have been necessary for safer passage of goods but also must have affected transaction costs e.g. as a result of haggling at each point of exchange. Disruption in any part of the chain would have adversely affected the whole chain. Transport of goods by sea was less dependent on such stages. Nevertheless, trade in necessities, such as foodstuffs in Central Europe, would have been greater than is evident from the archaeological records, because these are dominated by finds of durable items (Bartelheim 2013: 175). Foodstuffs are quite perishable and their origins can be difficult to trace based on their remains. Rivers (such as the Odra in Silesia) were used for transporting goods and domestic pack animals were available (Harding 2000, Uckelman 2013).

In line with the hypothesis of Bartelheim (2009a), any reduction in the economic surplus of food would have diminished the economic necessities available to UC populations to support their production of bronzes and would have reduced their interregional trade in bronzes. The problem would have been compounded 
when some deposits of tin ore and copper ore were exhausted or became more difficult to work. The overall result would be a decline in new additions to the stock of tin bronzes. It is possible that some UC settlements were eventually unable to produce tin bronzes or could only do so on a limited scale because their economic surplus declined and/or because their supplies of tin or copper ore were exhausted, or these ores became very costly to mine. In addition, fuel supplies for producing bronzes may have become scarcer (Svizzero, Tisdell 2016).

If some UC settlements did rely to a large extent on imports of necessities to support their role in tin bronze manufacture, they would have had to export commodities in return, such as bronze ware or materials for making bronze ware. This trade would be halted if for any reason imports of necessities were no longer forthcoming or if they could only be supplied on very unfavourable terms of exchange. However, there is no evidence of this heavy dependence. Therefore, it is doubtful whether disruption to the supply of tin bronzes for export could explain the eventual considerable reduction in the UC population in Silesia. It may, nevertheless, have caused economic disruption to some populations (Svizzero 2015, Tisdell, Svizzero 2015a). A decline in the overall supply of economic necessities relative to population levels associated with human-induced unfavourable ecological changes seems to be the more likely cause of the eventual decline of the presence of the UC population in Silesia.

In contrast to Kneisel (2012: 228), we consequently conclude that the decline in tin bronze production and trade involving bronzes was not the major reason (or even a significant one) for the vanishing of Silesian UC population. It probably was of little consequence for the standard of living in these settlements as judged by the availability of necessities. Despite this, it is accepted that the declining stock of tin bronzes in Silesian UC settlements and trade in these items were correlated with their falling populations. Furthermore, this may even have happened prior to the precipitous decline in UC populations in these settlements. Nevertheless, correlation does not prove causation. Even in the absence of the termination of bronzemaking and the trade in bronzes, it is likely that Silesian UC settlements would have experienced depopulation due to human-induced ecological change.

According to Knipper et al. (2016: 496): "because the raw materials of the metal alloys, the ores of copper and tin, have very restricted natural distribution areas and do not occur together, well established supraregional contacts were a major prerequisite for its production and the distribution of the finished products (Bartelheim 2009b, Bogucki 2004)." The degree and nature of geographic specialisation in the various stages of bronze production in the EBA needs more attention.

The above discussion raises the following question: What was the nature of the involvement of Silesian UC groups in economic activities associated with bronzes? It is unlikely that any (especially in Lower Silesia) were involved in the mining or winning of ores required for tin bronze production because these ores were evidently absent in Silesia (Harding 2013a, O'Brien 2013). As in Bohemia, copper was probably transported from the Alpine regions in the form of nuggets (Jiráñ et al. 2013: 804), particularly from Austria (Harding 2013a: 373). Tin may have been supplied in the form of ingots from areas in the Erzgebirge. Jirán̆ et al. (2013: 808) state: "The acquisition of tin by panning in watercourses running down the Erzgebirge (Ore Mountains) is considered likely by some scholars, given that these deposits are the only ores in central Europe." Consequently, the role of Silesian UC groups in the bronze industry would have been limited to acting as middle traders in the exchange of bronze ingots and bronze products, and to value-adding to imported bronze items or items either for their own use or for exchange. The extent of involvement of different UC Silesian groups in these activities probably varied. For example, some may have limited themselves entirely to entrepôt activities whereas others may have been more active in producing finished bronzeware.

Precisely how many members of each group were engaged in these activities does not seem to be known. The number of bronze smiths as a proportion of groups producing bronzes was probably low. However, account needs to be taken of those engaged in the provision of ancillary services. Nevertheless, the bulk of the Silesian UC population most likely consisted of agropastoralists with producers of non-essential commodities being few in number.

\section{DISRUPTION TO AND CHANGES IN TRADE ROUTES}

Increased disruption and or changes in trade routes may also have had an effect on the availability of tin bronzes in UC settlements. Most (maybe all) Silesian UC groups acted as "middle-traders" supplying bronze items to Baltic areas in return for amber which was 
then sent further south in return for bronze, tin or copper. Kneisel (2012) mentions the amber finds did not cease in the south of Europe after the decline of the UC population in the north, for instance after $1600 \mathrm{BC}$. This suggests that the northern UC population were by-passed in this trade. In the end, this population may have had little tin bronze to trade for reasons mentioned above. Those in the south may still have had bronze supplies and new routes for trading amber and bronzes may have opened up or some alternative existing ones may have become more dominant.

The interregional trade in amber and bronze which occurred in the EBA is well documented in the literature. There was movement of amber from the Baltic to the south of Europe and bronzes from the south moved northwards in Europe. Close contacts of UC populations with inhabitants of amber-producing areas of the southeastern Baltic are attested by many imports of UC metal types (Czebreszuk 2007: 365). Czebreszuk (2007) states that the beginning of the third millennium BC marked the beginning of the long distance trade in amber - which until then was considered to be a simple raw material. Amber became a precious cultural object and was exchanged between the Baltic and the Aegean from that period onwards. Approximately 4,000 amber artefacts from a total of 106 sites in Bohemia are known from the EBA. Bohemia is far richer in amber finds than all of the surrounding territories and was the main area targeted for trade in amber within the broader Central European region (Ernée 2012). Thus, towards the north, UC people were exporting bronze products (plus other items) to Scandinavia and importing amber from the Baltic coast.

The following questions need to be answered: To what extent did Silesia participate in the long distance exchange of bronze and amber? Were some UC communities in Silesia part of the exchange network supplying amber to Bohemia? What might have caused Silesian UC communities to be no longer involved in the trading of amber and bronze? What might have been the economic consequences of the decline in this trade or its cessation?

It is worthwhile noting that according to Ernée (2012), the massive inflow of amber into Bohemia stops at the end of the classical phase of the Únĕtice culture, that is about $1750 \mathrm{BC}$ and the targeted area of trade then shifts to southeast areas occupied by the Mad’arovce-Věteřov cultural complex. Ernée (2012: 71) comments: "The fundamental change in the distribution of amber finds documents not only the collapse in the amber trade in the decades around $1750 \mathrm{BC}$, but also the breakdown of the entire system of supra-regional contacts in a cornerstone of the advanced civilization of the classic Aunjetitz [a Únětice] culture."

Interestingly, the cessation of amber imports to Bohemia around $1750 \mathrm{BC}$ corresponds to the approximate time at which Pokutta (2013) concludes that the UC population virtually disappeared from Silesia. This suggests that there could be a connection between these events. If the Silesian UC population was heavily involved in the trade network supplying amber to Bohemia, it may have been unable to continue its involvement in this trade for reasons already discussed. Although De Navarro (1925) hypothesised that Bohemia obtained its supply of amber via the Elbe River, more recent evidence indicates that the major source of supply of amber to Bohemia probably was via a northerly route which included Lower Silesia. Ernée (2012: 71) states that to the extent to which one can speak of an "Amber Route", it would have run from the Polish Baltic Coast to Bohemia. More specifically, Czebreszuk (2013: 780) relies on the geographical location of finds of precious objects involved in the trade with Bohemia [see Czebreszuk 2013: Figure 42.1] to determine a northern corridor through which this trade passed. Czebreszuk (2013: 780) states that finds "...show a belt roughly about $100 \mathrm{~km}$ wide extending from the Moravian Gate, through Lower Silesia, Great Poland, Kuyavia, to the Vistula delta. The Early Bronze Age finds recorded in this area include amber, gold, artefacts, bronze objects imported from remote regions of Europe..." Consequently, the demise of the Silesian UC population in Lower Silesia is correlated with the massive reduction in the influx of amber to Bohemia about the middle of the $18^{\text {th }}$ century BC. However, as re-iterated below, it is doubtful whether cessation of the involvement of the Silesian UC population in this trade resulted in the apparent depopulation of these settlements in the late classical period.

There are many reasons why long distance trade routes can change permanently. Several are outlined in the existing literature (Jaeger 2012: 172-174, Jaeger, Czebreszuk 2010: 230-232). They include piracy and increasingly unfavourable rates of exchange (due to tolls) at different nodes in the trade network, for example, 'pinch points', the avoidance of which would add substantially to transport costs.

As for the economic impact on affected EBA communities of the decline or cessation of trade in luxury items, this is likely to be inconsequential unless 
gains from this trade are used to obtain essentials for living. The greater is the dependence on the luxury trade to procure essentials, the more negative will be economic consequences for the affected communities of a reduction or cessation of this trade (see Tisdell, Fairbairn 1984). This is consistent with the view of Bartelheim (2009a, 2013), and our view that the surplus of necessities is the relevant indicator of the economic status of EBA societies. Nevertheless, a reduction or the cessation of trade in luxuries which undermines the social structure of EBA communities could indirectly result in a decline in the amount of agropastoral supplies produced by them. Consequently, it could lead to social instability and social conflict and this could reduce economic production. Pokutta (2013), however, did not find any evidence of these changes in her study of the Únĕtice culture in Silesia. Therefore, we are of the opinion that a reduced agropastoral surplus is likely to have been the main cause of the eventual declining involvement of the UC population in the long-distance trade in amber and bronzes.

Note that although much attention has been given to trade in amber and bronze in the European EBA, several other commodities were traded as well (Harding 2013a, b, Jirán̆ et al. 2013). These included textiles and skins in the case of Silesian UC groups (Pokutta 2013). Furthermore, not all groups traded in the same commodities - some trade specialization occurred. For example, one reviewer of the earlier version of this article pointed out that there are no finds of amber in some areas of the Alps which were a source of unwrought copper. The Central European trade pattern was undoubtedly quite varied and complex and did not only involve the trading of prestige non-perishable goods. The archaeological record can give an inflated impression of the relative importance of prestige non-perishable goods in EBA trade (Bartelheim 2013: 175).

\section{CONCLUDING COMMENTS}

Why UC settlements in Silesia were rapidly depopulated in the $18^{\text {th }}$ Century BC remains uncertain. We hypothesise that it was mainly because they experienced considerable economic decline due to human-induced deterioration in ecosystems. Population pressures and the strains these placed on agricultural activity were the prime reasons for adverse ecosystem change. Ecological deterioration reduced the economic surplus and mineral depletion diminished the supply of tin bronzes. Ecosystem deterioration was not easily reversible. It took about two centuries before significant repopulation of areas previously occupied by UC groups in Silesia occurred. It is hard to believe that repopulation would not have been more rapid if the pattern of economic development of UC communities in Silesia had not had a marked adverse effect on the sustainability of ecosystems. In Silesia, the collapse of UC communities occurred over a period of around 200 years but there were already signs of impending collapse in the period 1900-1800 BC because immigration to that area fell significantly in this period.

Although Malthusian theory may provide a partial explanation of the decline in the economic prosperity of the Silesian UC populations in the $18^{\text {th }}$ century BC (based on the assumption of a decline in the marginal productivity of agriculture in response to population growth), this is a static theory. It fails to take account of human-induced changes to natural ecosystems which can shift the agricultural production function (as a function of the level of population) downward. Alterations in natural ecosystems can explain why following the depopulation of UC regions, they were not significantly resettled for so long. If only a (static) decline in marginal productivity had been involved, recovery of the productivity of agricultural land would have been relatively quick following the depopulation of these areas and would have halted declining population levels.

One cannot yet be sure of what types of difficult-toreverse natural ecosystem changes occurred as a result of agropastoral activity by Silesian UC populations. Invasion of agricultural land by weeds is one possibility and soil erosion might be another contributor. However, the general picture emerges is that UC populations in Silesia were unable to sustain their economic development because their agropastoral activities (driven by population growth) reduced their stock of natural capital to levels which halted and reversed their economic development. Furthermore, their ability to produce or trade in bronzes occurred because of the increased scarcity of resources needed to produce these. Because bronze was used mainly in the EBA to supply luxury or status goods rather than to add to the availability of productive equipment, this meant that bronze production did not improve the long-term prospects for economic growth of UC populations (Bartelheim 2013: 175).

Our view about the process involved in the decline of UC populations in Silesia in the $18^{\text {th }}$ Century BC can 
be summarised as follows: the agricultural surplus of their inhabitants declined in the long run because of their failure to curb population growth. Their growth in population levels resulted in increased pressure to raise the level of agricultural production. Eventually, the diminishing marginal productivity of agricultural production and adverse alterations to natural ecosystems (set in train by procedures to maintain agricultural productivity) made it increasingly difficult for the UC populations involved to maintain their per capita level of agricultural production. Once this problem occurred, no short-term solution to it was possible. Consequently, when the burden of maintaining food production became too high, residents in these settlements possibly began to migrate elsewhere and/or altered their culture. They did not wait until starvation became a significant problem. Significant migration may have occurred during three centuries beginning already in the $19^{\text {th }}$ century BC but there is no direct evidence of the timing or pattern of this aspect. This possible explanation of the disappearance of the UC population in Silesia partly relies on Malthusian considerations, but only partly because it stresses the importance of human-induced ecosystem changes, not covered in Malthusian type theories.

If the decline in the (apparent) prosperity of the UC inhabitants of Silesia was mainly attributable to Malthusian-like dynamics, this should have been rectified in the post-classical period once the level of the UC population fell considerably. For example, Pokutta's data (Table 1) suggests around a 56\% reduction in the population of the Silesian group occurred in the period 1800-1700 BC compared to the period 1900-1800 BC. However, population levels continued to fall. This is consistent with the hypothesis that the agricultural production function of this $\mathrm{UC}$ population had shifted downward. We believe that this was probably because agricultural developments adversely affected local ecosystems and set in motion ecological forces (such as reduced soil fertility and the increased occurrence and the spread of weeds) which continued to persist or to run their course even when the level of agricultural activity and population levels were reduced. In other words, the agricultural activities of the UC inhabitants caused disequilibrium in their natural ecosystems which once sufficiently disturbed, moved to adverse new states. Once in these new degraded states, it took a very long time after the human stressors were removed for them to recover sufficiently to support significant human resettlement of the affected areas.

\section{ACKNOWLEDGEMENTS}

We wish to thank Dr. Dalia Anna Pokutta for her generous comments on earlier drafts of this paper and the referees for their detailed and insightful comments on the previous version of this article. The usual caveat applies.

\section{REFERENCES}

BARTELHEIM M., 2009a: Elites and metals in the Central European Bronze Age. In: T. L. Kienlin, B. W. Roberts (Eds.): Metals and societies: studies in honour of Barbara S. Ottway. Pp. 34-47. Rudolf Habelt, Bonn.

BARTELHEIM M., 2009b: Die Nutzung mineralischer ressourcen in der Bronzezeit Mittel- und Südosteuropas. In: M. Bartelheim, H. Stäuble (Eds.): Die wirtschaftlichen grundlagen der Bronzezeit Europas. Pp. 178-188. Verlag Marie Leidorf $\mathrm{GmbH}$, Rahden Westfalen.

BARTELHEIM M., 2013: Innovation and tradition. the structure of early metal production in the North Alpine region. In: S. Burmeister, S. Hansen, M. Kunst, MüllerSchee $\beta \mathrm{el}$ (Eds.): Innovative technologies and social change in prehistory and antiquity. Pp. 169-180. Marie Leidorf, Rahden, Westfalia.

BATORA J., 1991: The Reflexion of Economy and Social Structure in the Cemeteries of the Chlopice-Veselé and Nitra Cultures, Slovenska Archeologia 39, 1 2: 91-142.

BOGAARD A., 2004: Neolithic farming in Central Europe: an archaebotanical study of crop husbandry practices. Routledge, London and New York.

BOGAARD A., FRASER R., HEATON T. H. E., WALLACE M., VAIGLOVA P., CHARLES M., JONES G., EVERSHED R. P., STYRING A. K., ANDERSEN N. H., ARBOGAST R.-M., BARTOSIEWICZ L., GARDEISEN A., KANSTRUP M., MAIER U., MARINOVA E., NINOV L., SCHÄFER M., STEPHAN E., 2013: Crop manuring and intensive land management by Europe's first farmers. Proceedings of the National Academy of Sciences 110, 31: 12589-12594.

BOGUCKI P., 1996: Sustainable and unsustainable adaptations by early farming communities of Northern Poland. Journal of Anthropological Archaeology 15, 3: 289-311.

BOGUCKI P., 2004: Introduction. In: P. Bogucki, P. J. Crabtree (Eds.): Ancient Europe 8000 B.C. - A.D. 1000, encyclopedia of the barbarian world, Vol. II, Bronze Age to Early Middle Ages (c. 3000 B.C. - 1000 A.D.). Pp. 3-5. Charles Scribners' Sons, New York.

CHILDE V. G., 1936: Man makes himself. Watts \& Co., London. CHILDE V. G., 1957: The Bronze Age. Past and Present 12: 2-15.

CUNLIFFE B., 2015: By steppe, desert and ocean: the birth of Eurasia. Oxford University Press, Oxford.

CZEBRESZUK J., 2007: Amber between the Baltic and the Aegean in the third and second millennia BC (an outline of major issues) Aegaeum Liege 27: 363-370. 
CZEBRESZUK J., 2013: The Bronze Age in the Polish Lands. In: H. Fokkens, A. Harding (Eds.): The Oxford handbook of the European Bronze Age. Pp. 767-86. Oxford University Press, Oxford.

DE NAVARRO J. M., 1925: Prehistoric routes between Northern Europe and Italy defined by the amber trade. The Geographical Journal 66, 6: 481-503.

DIAMOND J. M., 2005: Collapse: how societies choose to fail or succeed. Viking Press, New York.

DREIBRODT S., LUBOS C., TERHORST B., DAMM B., BORK H. R., 2010: Historical soil erosion by water in Germany: scales and archives, chronology, research perspectives. Quaternary International 222, 1-2: 80-95.

ERNÉE M., 2012: Jantar v české únětické kultuře - k počátkům jantarové stezky. Památky archeologické 103: 71-172.

ERNÉE M., MÜLLER J., RASSMANN K., 2009: Ausgrabung des frühbronzezeitlichen gräberfelds der Aunjetitzer Kultur von Prag-Miškovice. Vorläufige auswertung und erste ergebnisse der naturwissenschaftlichen untersuchungen: 14C-daten und metallanalysen. In: K.-F. Rittershofer, J. K. Koch (Eds.): Germania. Pp. 355-410. Verlag Philip von Zabern, Frankfurt.

ERNÉE M., PROFANTOVÁ N., BŘEZINOVÁ H., FRÁNA J., MAJER A., STRÁNSKÁ P., 2011: Pohřebiště únětické kultury v Klecanech, okr. Praha-východ. Archeologické rozhledy 63: 307-330.

HANSEN S., 2010: Überausstattungen in gräbern und horten der Frühbronzezeit: muster sozialen wandels? Universitätsforschungenzur Prähistorischen Archäologie 90: 151-173.

HARDING A., 2013a: Trade and exchange. In: H. Fokkens, A. Harding (Eds.): Oxford handbook of the European Bronze Age. Pp. 370-381. Oxford University Press, Oxford.

HARDING A., 2013b: Salt production in the Bronze Age. In: H. Fokkens, A. Harding (Eds.): The Oxford handbook of the European Bronze Age. Pp. 501-507. Oxford University Press, Oxford.

HARDING A. F., 2000: European societies in the Bronze Age. Cambridge University Press, Cambridge.

HASSAN F. L., 1981: Demographic archaeology. Academic Press, New York and London.

HAUG G. H., GÜNTHER D., PETERSON L. C., SIGMAN D. M., HUGHEN K. A., AESCHLIMANN B., 2003: Climate and the collapse of Maya Civilization. Science 299, 5613: 1731-1735.

HAYWOOD J., 2010: The ancient world. Quercus Publishing, London.

JAEGER M., 2012: Kościan group of Únětice culture and fortified settlement in Bruszczewo. Their role in micro and macro-regional exchange. In: M. Jaeger, J. Czebreszuk, K. P. Fischl (Eds.): Enclosed space - open society. Contact and exchange in the context of Bronze Age fortified settlements in Central Europe. Pp. 167-176. SAO/SPEŚ 9, Poznań-Bonn.

JAEGER M., CZEBRESZUK J., 2010: Does a periphery look like that? The cultural landscape of the Únětice culture's Kościan group. In: Kiel Graduate School "Human development in landscapes" (Ed.): Landscapes and human development: the contribution of European archaeology. Pp. 217-235. Dr Rudolf Habelt GmbH, Bonn.

JIRÁŇ L., SALAŠ M., KRENN-LEEB A., 2013: The Czech lands and Austria in the Bronze Age. In: H. Fokkens, A. Harding (Eds.): The Oxford handbook of the European Bronze Age. Pp. 787-812. Oxford University Press.

JOCKENHÖVEL A., 2013: Germany in the Bronze Age. In: H. Fokkens, A. Harding (Eds.): The Oxford handbook of the European Bronze Age. Pp. 723-745. Oxford University Press.

KIENLIN T. L., STÖLLNER T., 2009: Singen copper, alpine settlement and Early Bronze Age mining: is there a need for elites and strongholds? In: T. L. Kienlin, B. W. Roberts (Eds.): Metals and societies: studies in honour of Barbara S. Ottway. Pp. 67-104. Rudolf Habelt, Bonn.

KNEISEL J., 2012: The problem of the middle Bronze Age inception in Northeast Europe or: did the Únĕtice society collapse? In: J. Kneisel, W. Kirleis, M. D. Corso, N. Taylor, V. Tiedtke (Eds.): Collapse or continuity? Environment and development of Bronze Age human landscapes. Pp. 209-234. Verlag Dr. Rudolf Habelt GmbH, Bonn.

KNIPPER C., FRAGATA M., NICKLISCH N., SIEBERT A., SZÉCSÉNYI-NAGY A., HUBENSACK V., METZNERNEBELSICK C., MELLER H., ALT K. W., 2016: A distinct section of the early Bronze Age society? Stable isotope investigations of burials in settlement pits and multiple inhumations of the Únětice culture in central Germany. American Journal of Physical Anthropology 159, 3: 496-516.

LASAK I., FURMANEK M., 2008: Bemerkungen zum vermutlichen wehrobjekt der Aunjetitzer Kultur in Radłowice in Schlesien. In: J. Müller, J. Czebreszuk, S. Kadrow (Eds.): Defensive structures from Central Europe to the Aegean in the $3^{\text {rd }}$ and $2^{\text {nd }}$ millennia B.C. Studia nad pradziejami Europy Środkowej. Pp. 123-134. Poznań-Bonn.

MONTGOMERY J., JAY M., 2013: The contribution of skeletal isotope analysis to understanding the Bronze Age in Europe. In: H. Fokkens, A. Harding (Eds.): The Oxford handbook of the European Bronze Age. Pp. 179-196. Oxford University Press.

MOSKAL-DEL HOYO M., LITYŃSKA-ZAJĄC M., KORCZYŃSKA M., CYWA K., KIENLIN T. L., CAPPENBERG K., 2015: Plants and environment: results of archaeobotanical research of the Bronze Age settlements in the Carpathian Foothills in Poland. Journal of Archaeological Science 53: 426-444. doi: 10.1016/j.jas.2014.10.024

MÜLLER J., 2012: Changes in the Bronze Age: social economical and/or ecological causes? In: J. Kneisel, W. Kirleis, M. D. Corso, N. Taylor, V. Tiedtke (Eds.): Collapse or continuity? Environment and development of Bronze Age human landscapes. Pp. 257-266. Verlag Dr. Rudolf Habelt GmbH, Bonn.

MÜLLER J., CZEBRESZUK J., J. K. (Eds.), 2010: Bruszczewo II. Badanic mikroregiona osadniczego z terena wiekoploski/ aus-grabungen und forschungen in einer prähistorischen siedlungskammer grosspolens. Rudolf Habelt, Bonn.

O'BRIEN W., 2013: Bronze Age copper mining in Europe. In: H. Fokkens, A. Harding (Eds.): The Oxford handbook of the European Bronze Age. Pp. 438-453. Oxford University Press. 
PIWOCKI M., S. PRZENIOSLO, 2004: Mineral raw materials and commodities of Poland. Przeglad Geologiczny 52, 8/2: 744-752.

POKUTTA D. A., 2013: Population dynamics, diet and migration of the Unertice Culture in Poland. Department of Historical Studies, University of Gothenburg, Gothenburg.

RAVENSTEIN E., 1885: The laws of migration. The Journal of Statistical Society of London 48: 167-235.

RAVENSTEIN E., 1889: The laws of migration. Journal of the Royal Statistical Society 52: 241-305.

ROBERTS B. W., THORTON C. P., PIGOTT V. C., 2009: Development of metallurgy in Eurasia. Antiquity 83: $112-122$.

SVIZZERO S., 2015: The collapse of the Únětice culture: economic explanation based on the 'Dutch Disease'. Czech Journal of Social Sciences, Business and Economics 4, 3: 6-18.

SVIZZERO S., TISDELL C. A., 2014: Inequality and wealth in ancient history: Malthus' theory reconsidered. Economics \& Sociology 7, 3: 223-240. doi: 10.14254/2071-789X.2014/7-3/17

SVIZZERO S., TISDELL C. A., 2016: Input shortages and the lack of sustainability of bronze production by the Únĕtice. Economics, ecology and the environment, Working Paper No. 202. School of Economics, The University of Queensland, Brisbane.

TISDELL C. A., 2005: Economics of environmental conservation. Edward Elgar, Cheltenham, UK and Northampton, MA, USA.

TISDELL C. A., 2015: Sustaining biodiversity and ecosystem functions: economic issues. Edward Elgar, Cheltenham, UK and Northampton, MA, USA.

TISDELL C. A., FAIRBAIRN T. I., 1984: Subsistence economies and unsustainable development and trade. Journal of Development Studies 20: 227-241.

TISDELL C. A., SVIZZERO S., 2015a: The collapse of some ancient economies due to unsustainable mining development (a draft). Economic theory, applications and issues, Working Paper No. 72. School of Economics, The University of Queensland, Brisbane.

TISDELL C. A., SVIZZERO S., 2015b: The Malthusian Trap and the development in pre-industrial societies: a view differing from the standard one. Social economics, policy and development, Working Paper No. 59. School of Economics, The University of Queensland, Brisbane.

TISDELL C. A., SVIZZERO S., 2017a: Optimization theories of the transition from foraging to agriculture: A critical assessment and proposed alternatives. Social Evolution \&
History: Studies in the Evolution of Human Societies 16, 1: 3-30.

TISDELL C. A., SVIZZERO S., 2017b: The Ability in Antiquity of Some Agrarian Societies to Avoid the Malthusian Trap and Develop. Forum for Social Economics: 1-26. doi: 10.1080/07360932.2017.1356344

TODARO M. P., 1969: A model of labor migration and urban unemployment in less developed countries. The American Economic Review 59, 1: 138-148.

UCKELMAN M., 2013: Land transport in the Bronze Age. In: H. Fokkens, A. Harding (Eds.): The Oxford handbook of the European Bronze Age. Pp. 398 413. Oxford University Press.

WEISDORF J. L., 2005: From foraging to farming: explaining the Neolithic Revolution. Journal of Economic Surveys 19: 561-586. doi: 10.1111/j.0950-0804.2005.00259.x

ZICH B., 2010: Die frühbronzezeitliche umgeburg des fundes mit der himmels shoebe von Nebra. In: H. Meller, F. Bertemes (Eds.): Der griff nach den sternen (proceedings of the international symposium held in Halle, February, 2005). Pp. 97-117. Landesmuseums for Vorgeschichle Halle (Saale).

Clement A. Tisdell*

School of Economics, The University of Queensland, St Lucia, 4072, Queensland, Australia Tel: +61 733656570

Email: c.tisdell@economics.uq.edu.au

\section{Serge Svizzero}

Faculté de Droit etd'Economie, Université de La Réunion, 15 Avenue René Cassin. CS 9003, 97744 Saint Denis, France

Tel: +262 262138258

Email: serge.svizzero@univ-reunion.fr

* Corresponding author. 